\title{
Characterization of Ectopic Colonies That Form in Widespread Areas of the Nervous System with Neural Stem Cell Transplants into the Site of a Severe Spinal Cord Injury
}

\author{
Oswald Steward, ${ }^{1,2,3,4}$ Kelli G. Sharp, ${ }^{1}$ Kelly Matsudaira Yee, ${ }^{1}$ Maya N. Hatch, ${ }^{1}$ and Joseph F. Bonner ${ }^{1}$ \\ ${ }^{1}$ Reeve-Irvine Research Center, Departments of ${ }^{2}$ Anatomy and Neurobiology, ${ }^{3}$ Neurobiology and Behavior, and ${ }^{4}$ Neurosurgery, University of California at \\ Irvine School of Medicine, Irvine, California 92697-4265
}

\begin{abstract}
We reported previously the formation of ectopic colonies in widespread areas of the nervous system after transplantation of fetal neural stem cells (NSCs) into spinal cord transection sites. Here, we characterize the incidence, distribution, and cellular composition of the colonies. NSCs harvested from E14 spinal cords from rats that express GFP were treated with a growth factor cocktail and grafted into the site of a complete spinal cord transection. Two months after transplant, spinal cord and brain tissue were analyzed histologically. Ectopic colonies were found at long distances from the transplant in the central canal of the spinal cord, the surface of the brainstem and spinal cord, and in the fourth ventricle. Colonies were present in $50 \%$ of the rats, and most rats had multiple colonies. Axons extended from the colonies into the host CNS. Colonies were strongly positive for nestin, a marker for neural precursors, and contained NeuN-positive cells with processes resembling dendrites, GFAP-positive astrocytes, APC/CC1-positive oligodendrocytes, and Ki-67-positive cells, indicating ongoing proliferation. Stereological analyses revealed an estimated 21,818 cells in a colony in the fourth ventricle, of which 1005 (5\%) were Ki-67 positive. Immunostaining for synaptic markers (synaptophysin and VGluT-1) revealed large numbers of synaptophysinpositive puncta within the colonies but fewer VGluT-1 puncta. Continuing expansion of NSC-derived cell masses in confined spaces in the spinal cord and brain could produce symptoms attributable to compression of nearby tissue. It remains to be determined whether other cell types with self-renewing potential can also form colonies.
\end{abstract}

Key words: growth factors; neural stem cells; spinal cord injury; stereology

\section{Introduction}

There is great interest in the possible use of stem cells for therapies for a wide range of neurological disorders. Several clinical trials are approved for enrollment or already underway involving transplantation of stem cells with self-renewing (proliferative) potential or stem cell-derived differentiated cell types that could be contaminated with cells that are capable of proliferation. Among these are trials involving transplants of neural stem cells (NSCs) for amyotrophic lateral sclerosis (ALS; Feldman et al., 2014) and spinal cord injury. A major concern for all therapies involving implantation of cells with proliferative potential into the CNS is the possibility of continued proliferation resulting in space-occupying masses. Cells being used in current ongoing tri-

Received July 23, 2014; revised Aug. 29, 2014; accepted Sept. 4, 2014.

Author contributions: 0.S. designed research; K.G.S. and K.M.Y. performed research; O.S., K.G.S., K.M.Y., M.N.H., and J.F.B. analyzed data; 0. .S. wrote the paper.

This work was supported by National Institutes of Health Contract N01-NS-3-2353 and Grant R01 NS047718. We thank Dr. Paul Lu for performing spinal cord injury surgeries and the transplants. Thanks also to Lori Graham for preparing the NSCs and Laine Butler, Jessica Dzubnar, Sabhya Rana, Ardi Gunawan, Jennifer Yonan, and Jamie Mizufuka for assistance in surgical procedures, animal care, and neurohistology. We also thank Oscar Mendez and Eric Gold for help with ApoTome microscopy and Drs. B. Cummings and A. J. Anderson for the use of the ApoTome system.

Correspondence should be addressed to Dr. Oswald Steward, Reeve-Irvine Research Center, University of California, Irvine, 1105 Gillespie Neuroscience Research Facility, Irvine, CA 92697-4265. E-mail: osteward@uci.edu.

DOI:10.1523/JNEUROSCI.3066-14.2014

Copyright $\odot 2014$ the authors $\quad 0270-6474 / 14 / 3414013-09 \$ 15.00 / 0$ als have been tested extensively in this regard, but without knowing what to look for, it is possible that things can be missed. Growth of any cell mass in the nervous system is a concern, especially cell masses that grow in small confined spaces, in which expansion of the mass could damage surrounding neural tissue.

Here, we characterize ectopic colonies that form in widespread areas of the nervous system after transplantation of freshly isolated NSCs from E14 rat embryos that were treated with a cocktail of growth factors into the cavity resulting from a complete spinal cord transection. We made this discovery in our replication (Sharp et al., 2014) of a study that reported exuberant axon outgrowth from transplants of NSCs and enhanced recovery of locomotor function after spinal cord transection in rats ( $\mathrm{Lu}$ et al., 2012). Our results confirmed that NSCs could expand to fill the cavity at the site of the spinal cord injury, although this depended on the method of engraftment (Sharp et al., 2014). We were also surprised to discover ectopic colonies of graft-derived cells at long distances from the transplant site in the central canal of the spinal cord, on the surface of the spinal cord and brain, and in the fourth ventricle of the brainstem.

We reported previously the existence of these colonies in a brief "Correspondence" (Steward et al., 2014). This brief communication did not include data on how common the colonies were, whether multiple colonies were present in individual rats, and whether the colonies contained differentiated neurons and 
glia. Although we documented Ki-67-positive cells, we did not determine the proportion of these relative to the overall cellular composition of the colonies.

We show here that colonies are common after this transplantation procedure; most rats with colonies had colonies at multiple sites in the nervous system. Colonies were strongly positive for nestin, indicating the presence of immature cells, but also contained differentiated NeuN-positive neurons with dendritic processes, differentiated astrocytes, and a few APC/CC1-positive oligodendrocytes. Neurons and oligodendrocytes were GFP positive, indicating their origin from the transplanted NSCs. Surprisingly, GFAP-positive astrocytes were not GFP positive. Our results indicate that NSCs at locations distant from the transplant differentiate primarily into neurons and that host astrocytes migrate in. Together, these data extend our understanding of the nature of ectopic colonies that can form after NSC transplants.

\section{Materials and Methods}

Detailed experimental protocols have been described previously (Sharp et al., 2014). Spinal cord injuries were done in 10- to 11-week-old female Fischer 344 rats from Harlan Labs. NSCs were isolated from timedpregnant female rats [strain: F344- $\mathrm{Tg}$ (UBC-EGFP) F455Rrrc; RRRC \#00307; Rat Resource and Research Center]. Experimental protocols on spinal cord injured rats were approved by the Institutional Animal Care and Use Committee (IACUC) at the University of California, Irvine (UCI). Procedures used to collect fetal NSCs were approved by the IACUC at the Veterans Administration Hospital San Diego (VASD).

\section{Spinal cord injury}

Rats were anesthetized with ketamine $(67 \mathrm{mg} / \mathrm{kg})$ and xylazine $(0.7 \mathrm{mg} /$ $\mathrm{kg}$ ), and spinal cord transections were performed as described previously (Lu et al., 2012; Sharp et al., 2014). After recovering from the anesthetic, rats were housed three to four per cage on water-circulating jacketed heating pads. Rats received lactated Ringer's solution $(20 \mathrm{ml} / \mathrm{kg}$, s.c.) every $6 \mathrm{~h}$ for the first $3 \mathrm{~d}$, banamine $(2 \mathrm{ml} / \mathrm{kg}$, s.c. $)$ every $12 \mathrm{~h}$ for the first $3 \mathrm{~d}$, and ampicillin ( $3 \mathrm{ml} / \mathrm{kg}$, s.c.) every $24 \mathrm{~h}$ for $14 \mathrm{~d}$ or until bladder function returned. Rats received sulfamethoxazole and trimethoprim (200 mg/5 ml and $40 \mathrm{mg} / 5 \mathrm{ml})$ and amoxicillin $(250 \mathrm{mg} / 5 \mathrm{ml})$ in drinking water $(5-10 \mathrm{ml}$ per $400-500 \mathrm{ml}$ of water) for the duration of the study and were fed Nutri-Cal and DietGel for the first 2 weeks. Bladders were manually expressed two to three times daily until reflex bladder function returned.

\section{Cell preparation}

Cells were prepared in the laboratory of Dr. Paul Lu at the VASD and were delivered to UCI on the day of the grafting procedure. Timedpregnant female rats were deeply anesthetized with an intraperitoneal injection of Euthasol $(100 \mathrm{mg} / \mathrm{kg})$, the abdominal cavity was opened under aseptic surgical procedures, and the uterus was removed and placed in a Petri dish with cold PBS on ice. Embryos were removed, and GFP-positive embryos (identified with a "NightSea" flashlight) were collected. One and one-half GFP-positive E14 embryos were used for each rat to be transplanted.

Spinal cords were dissected as described previously (Sharp et al., 2014) transferred to $15 \mathrm{ml}$ conical tubes with $1 \mathrm{ml}$ of ice cold HBSS (calcium and magnesium free) and $1 \mathrm{ml}$ of $0.25 \%$ trypsin-EDTA for the final trypsin concentration of $0.125 \%$. Tubes were placed in a $37^{\circ} \mathrm{C}$ water bath for $8-15 \mathrm{~min}$, and then $10 \mathrm{ml}$ of DMEM containing $10 \%$ FBS was added to stop the trypsin reaction. Tubes were centrifuged at $2500 \mathrm{rpm}$ for 2 min, the supernatant was removed, $1 \mathrm{ml}$ of Neurobasal medium with 1:50 B27 growth-promoting supplement was added, the pellet was gently resuspended with a $1 \mathrm{ml}$ pipetman and large sterile pipette tip, and then a fire-polished Pasteur pipette with large bore was used to triturate the cell suspension. Resuspension was continued by triturating with progressively smaller-diameter fire-polished pipettes, and cells were pelleted by centrifugation at $2500 \mathrm{rpm}$ for $2 \mathrm{~min}$. The supernatant was removed, and the pellet was resuspended in $1-2 \mathrm{ml}$ of Neurobasal medium. Then the cell suspension was filtered through a $45 \mu \mathrm{m}$ cell strainer and collected into a sterile $50 \mathrm{ml}$ tube. The above procedures were performed at VASD and required $\sim 2 \mathrm{~h}$ per preparation, and the cells were then transported to UCI.

Immediately before transplantation, cells were counted with a cytometer, centrifuged at $2500 \mathrm{rpm}$ for $2 \mathrm{~min}$, and resuspended at a final concentration of $250,000 \mathrm{cells} / \mu \mathrm{l}$ in a fibrin and thrombin cocktail. The fibrin and thrombin/cocktail/cell mixture was loaded in separate glass pulled pipettes. Injection parameters are described below.

\section{Preparation of fibrogen/thrombin/cocktail}

The growth factor cocktail contained the following agents: recombinant human brain-derived neurotrophic factor $(50 \mu \mathrm{g} / \mathrm{ml}$; catalog \#452-02; Peprotech), recombinant human neurotrophin-3 (NT-3; $50 \mu \mathrm{g} / \mathrm{ml}$; Peprotech-03; Peprotech), calpain inhibitor III (MDL28170; $50 \mu \mathrm{M}$; catalog \#M6690; Sigma-Aldrich), human platelet-derived growth factor-AA (10 $\mu \mathrm{g} / \mathrm{ml}$; catalog \#P3076; Sigma-Aldrich), mouse insulin-like growth factor-1 (10 $\mu \mathrm{g} / \mathrm{ml}$; catalog \#I8779; Sigma-Aldrich), murine epidermal growth factor (10 $\mu \mathrm{g} / \mathrm{ml}$; catalog \#E1257; Sigma-Aldrich), basic human fibroblast growth factor $(10 \mu \mathrm{g} / \mathrm{ml}$; catalog \#F0291; Sigma-Aldrich), acidic human fibroblast growth factor $(10 \mu \mathrm{g} / \mathrm{ml}$; catalog \#F5542; SigmaAldrich), rat glial cell line-derived neurotrophic factor $(10 \mu \mathrm{g} / \mathrm{ml}$; catalog \#G1401; Sigma-Aldrich), and human hepatocyte growth factor (10 $\mu \mathrm{g} /$ $\mathrm{ml}$; catalog \#H9661; Sigma-Aldrich). Each original agent was reconstituted with $1 \times$ PBS. Rat fibrinogen $(100 \mathrm{mg} / \mathrm{ml}$; catalog \#F6755; SigmaAldrich) and $1 \times$ PBS were combined with the growth factor cocktail and made into aliquots with a final concentration of $25 \mathrm{mg} / \mathrm{ml}$. Rat thrombin ( $100 \mathrm{U} / \mathrm{ml}$; catalog \#T5772; Sigma-Aldrich) and $10 \mathrm{~mm} \mathrm{CaCl}_{2}$ were combined with the growth factor cocktail and made into aliquots with a final concentration of $25 \mathrm{U} / \mathrm{ml}$. One aliquot of rat fibrinogen/growth factor cocktail $(25 \mathrm{mg} / \mathrm{ml})$ and one aliquot of rat thrombin/growth factor cocktail $(25 \mathrm{U} / \mathrm{ml})$ were used on the day of transplantation surgeries.

\section{Grafting procedures}

Rats received transection injuries on 4 separate days and received NSC grafts $\sim 2$ weeks later. Rats were reanesthetized with ketamine/xylazine as above. Rats were placed in a stereotaxic device with a tail clamp, the skin over the laminectomy site was incised, and muscle and scar tissue were dissected to expose the original laminectomy site, taking care not to reinjure the dura mater and spinal cord. Transplants were made using two methods as described below.

Method 1. The dura mater was incised, and scar tissue was aspirated to create a cavity, taking care not to injure the spinal cord. Then $3.0 \mu \mathrm{l}$ of the fibrogen/cocktail/cells was injected into the epicenter of the lesion using a Picospritzer (catalog \#052-0500-900; Parker), and a preformed gel made of $50 \mu \mathrm{g} / \mathrm{ml}$ fibrin and $50 \mathrm{~g} / \mu \mathrm{l}$ thrombin was placed over the cavity. Then $0.375 \mu \mathrm{l}$ of thrombin/cocktail/cells was injected into eight sites (two sites lateral to the epicenter and three sites rostral and three sites caudal to the epicenter). Nine rats received transplants via Method 1.

Method 2. A series of nine holes were made in the dura mater using a 1 cc insulin syringe with a 30 gauge needle (catalog \#305934; BD Biosciences). Three holes were rostral to the epicenter, three were at the epicenter, and three were caudal to the epicenter. Each hole was expanded until the ventral spinal column was identified, leaving the scar tissue intact, taking care not to damage the intact spinal cord. Using a Picospritzer, $1.5 \mu \mathrm{l}$ of fibrogen/cocktail/cells was injected into the central site at epicenter, $1.0 \mu \mathrm{l}$ was injected in the two lateral points at the epicenter, and $0.33 \mu \mathrm{l}$ was injected into each site rostral and caudal to the epicenter. Then the same procedure was repeated with the mixture of thrombin/ cocktail/cells. Eleven rats received transplants via Method 2.

Both transplantation methods delivered a total of $6 \mu \mathrm{l}$ of fibrin/throm$\mathrm{bin} /$ cocktail/cells mixture into the lesion site and $\sim 250,000 \mathrm{cells} / \mu \mathrm{l}$ for a total of $\sim 1.5 \times 10^{6}$ cells per graft. After achieving hemostasis, overlying muscles were sutured, and the skin was closed using wound clips. Postoperative care was as described above.

Timing of procedures. NSCs were harvested in the morning at the VAMC between 7:00 A.M. and 9:00 A.M. The cells were transported to UCI on ice, where the first transplant surgery was performed at $\sim 11: 00$ A.M., with other rats receiving transplants at intervals of $\sim 30 \mathrm{~min}$. Transplants were done on 4 different days. 
A
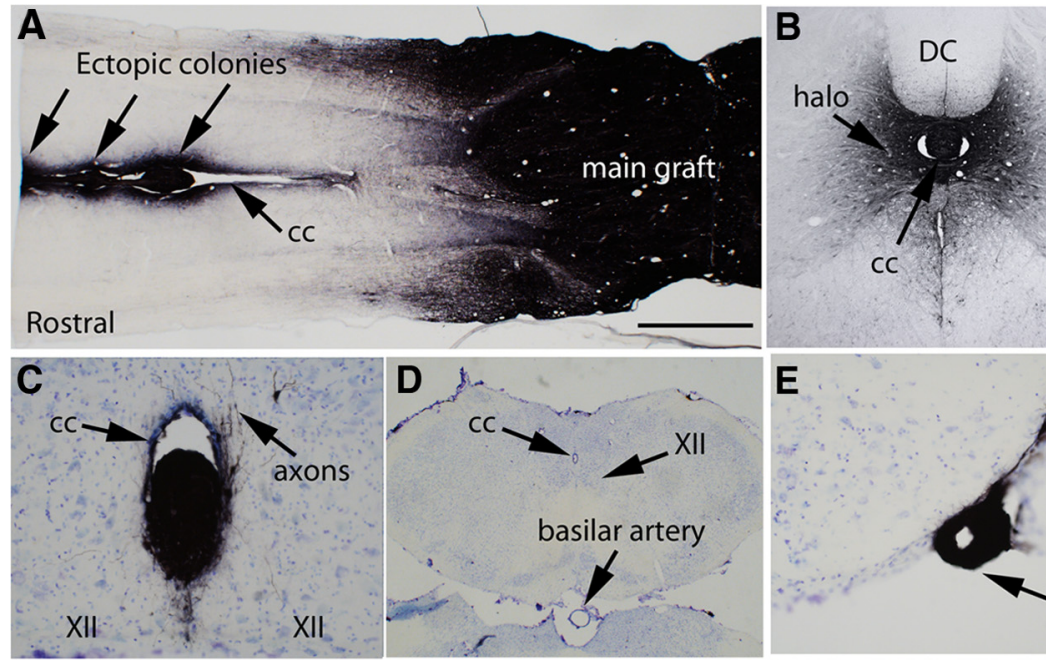

basilar artery
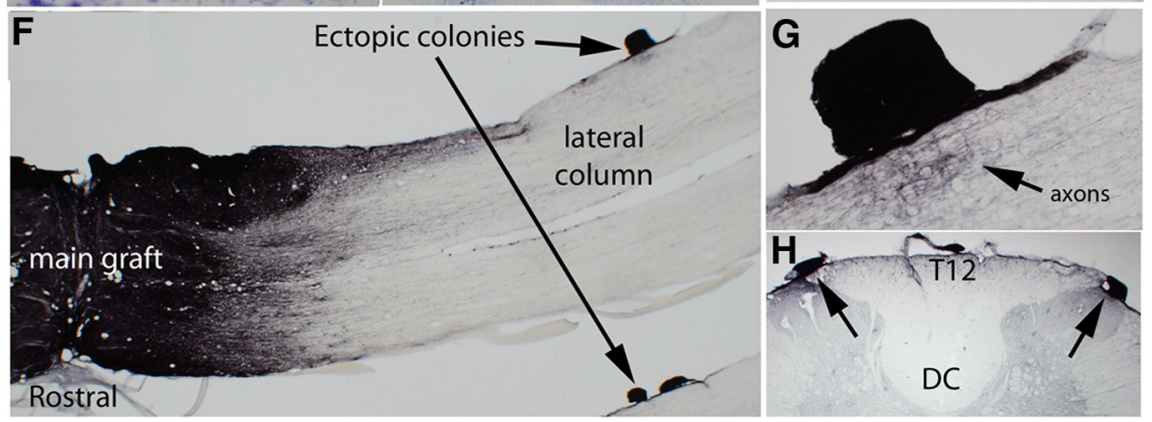

Figure 1. Examples of ectopic colonies of graft-derived cells. $A$, Masses of GFP-positive cells in the central canal $\sim 4-7 \mathrm{~mm}$ away from the main body of the graft in rat 28. Arrows indicate three masses. cc, Central canal. $\boldsymbol{B}$, A mass of GFP-positive cells in the central canal at approximately C 8 in rat 28. DC, Dorsal column; $c$, central canal. C, Ectopic mass in the central canal (cc) in the caudal brainstem. XII indicates the caudal extension of the hypoglossal nucleus. Axons can be seen extending from the colony into the parenchyma of the brainstem. D, Low-power image of the caudal brainstem to provide context for the image in $\boldsymbol{C}$. $E$, Ectopic mass attached to the ventrolateral brainstem in the same section as the colony in the central canal shown in $\boldsymbol{C}$. $\boldsymbol{F}$, Ectopic colonies attached to the surface of the spinal cord in rat 25. $\boldsymbol{E}$, High-magnification view of the ectopic colony in $\boldsymbol{D}$. Arrow indicates the nest of GFP-positive axons adjacent to the ectopic colony. $\boldsymbol{H}$, Two masses of GFP-positive cells attached to the surface of the spinal cord near the dorsal horn and dorsal root entry zone at T12 in rat 28. Scale bar: (in $A) A, F, 1 \mathrm{~mm} ; C, E, 100 \mu \mathrm{m} ; \boldsymbol{D}, \boldsymbol{H}, 500 \mu \mathrm{m}$; G, $250 \mu \mathrm{m}$

\section{Tissue preparation and immunostaining}

Rats were killed 9-10 weeks after injury via injection of Euthasol (100 $\mathrm{mg} / \mathrm{kg}$ ) and were perfused transcardially with $4 \%$ paraformaldehyde in $0.1 \mathrm{~m}$ phosphate buffer, $\mathrm{pH}$ 7.4. Tissue was postfixed in $4 \%$ paraformaldehyde in $0.1 \mathrm{M}$ phosphate buffer, $\mathrm{pH} 7.4$, at $4^{\circ} \mathrm{C}$ overnight and then cryoprotected in $27 \%$ sucrose.

A $15 \mathrm{~mm}$ block of spinal cord containing the lesion was embedded in OCT Tissue-Tek (catalog \#25608-930; Sakura Finetek) and frozen. Cryostat sections were taken in the horizontal plane at $30 \mu \mathrm{m}$, and sections were collected in serial order in PBS with $0.05 \%$ sodium azide. Blocks of the spinal cord at spinal levels C2, C4, C6, C8, T6, T8, T10, T12, L1/2, and $\mathrm{L} 4$ were sectioned in the transverse plane at $20 \mu \mathrm{m}$. Brains were prepared as above and sectioned at 20 or $40 \mu \mathrm{m}$ thickness in the coronal plane. Selected sections with the ectopic cell masses were immunostained for nestin, GFAP, NeuN, APC/CC1, Ki-67, allograft inflammatory factor 1 (IBA1), synaptophysin, and VGLUT1.

For immunostaining, sections were washed in TBS, blocked in TBS with $0.1-0.3 \%$ Triton X-100 and 5\% normal donkey or goat serum, and then incubated overnight in primary antibody cocktails containing the following, as needed: rabbit anti-GFP (1:1500; catalog \#A-11122; Invitrogen), mouse anti-GFAP (1:1000; catalog \#G-3893; Sigma-Aldrich), mouse anti-SMI-312 for neurofilament (NF; 1:1000; catalog \#ab24574; Abcam), mouse anti-MAP2 (1:500; catalog \#M9942; Sigma-Aldrich), rabbit anti-Ki-67 (1:200; catalog \#RM9106-S; Thermo Fisher Scientific), mouse anti-nestin (catalog \#MAB353; EMD Millipore), mouse antiNeuN (1:200; catalog \#MAB377; EMD Millipore), mouse anti-APC/CC1
(1:400; catalog \#OP-80; EMD Millipore), rabbit anti-Ibal (1:1000; catalog \#019-19741, Wako), mouse anti-synaptophysin (1:100; catalog \#MAB368; EMD Millipore), or guinea pig anti-VGlUT1 (1:2000; catalog \#135-304; Synaptic Systems). Sections were washed in TBS and then incubated with fluorophoreconjugated secondary antibodies diluted 1:250 in TBS with $5 \%$ normal donkey or goat serum. For GFP, donkey anti-rabbit Alexa Fluor-488 (catalog \#A-21206; Invitrogen) was used. For GFAP, NeuN, APC/CC1, synaptophysin, and NF, donkey anti-mouse Alexa Fluor-594 (catalog \#A-21203; Invitrogen) was used. For Ki67, goat anti-rabbit Alexa Fluor-594 (catalog \#A-11037; Invitrogen) was used. For VGLUT1, donkey anti-guinea pig CF 568 (500 $\mu$ l; catalog \#20377; Biotium) was used. After washes, sections were stained in $1 \mu \mathrm{g} / \mathrm{ml}$ Hoechst 33258 (catalog \#H-3569; Invitrogen) for $5 \mathrm{~min}$, washed in TBS, and mounted on gelatin-subbed slides. Slides were coverslipped with Vectashield (catalog \#H-1000; Vector Laboratories).

For GFP immunostaining, free-floating sections were washed in TBS, treated in $1 \%$ hydrogen peroxide $15 \mathrm{~min}$, washed again in TBS, and then blocked in TBS with $0.1 \%$ Triton X-100 and 5\% normal donkey serum. Sections were incubated in rabbit anti-GFP (1:1500; catalog \#A-11122; Invitrogen) overnight, washed in TBS, and then incubated with donkey antirabbit HRP secondary antibody (1:250; catalog \#711-036-152; Jackson ImmunoResearch) for $1-2 \mathrm{~h}$. Sections were washed in TBS and reacted with nickel enhanced DAB (catalog \#PK4100; Vector Laboratories), rinsed, and then mounted on gelatin-subbed slides. Slides were dehydrated through graded ethanols, cleared in xylenes, and coverslipped with DPX.

Image acquisition and processing. A subset of images (see Results) were acquired using an Axio Imager M2 ApoTome System (Zeiss), which has a resolution comparable with a laser scanning confocal microscope. Monochrome images were pseudocolored with AxioVision software. Images are flattened Z-stacks with $x, y$ maximum projections.) Image brightness and contrast was adjusted in Adobe Photoshop to make digital images comparable with what is seen in the microscope and to make images suitable for publication. All image processing followed the Society of Neuroscience Policy on Image Manipulation.

\section{Results}

Spinal cords from rats that received NSC transplants were prepared by sectioning a $15 \mathrm{~mm}$ block containing the lesion site in the horizontal plane and taking cross-sections through the remainder of the spinal cord rostral and caudal to the lesion block. As noted previously, we found that the nature of the transplants differed depending on the method of grafting. In rats grafted with Method 1, NSCs expanded to completely fill in the space left at the injury site and integrated extensively at the rostral and caudal ends of host tissue (Fig. 1A). Grafts were more variable in rats grafted with Method 2, and in many rats, the grafts did not fill the lesion site. With both grafting techniques, there was exuberant axon outgrowth from the grafts into the host spinal cord, which is best seen in sections immunostained using DAB as the chromogen. Highly arborized GFP-positive cells were also evident in the host parenchyma 1-2 $\mathrm{mm}$ from the graft margin. 
Table 1. Location of ectopic cell masses

\begin{tabular}{|c|c|}
\hline Location & Distance from graf \\
\hline \multicolumn{2}{|c|}{ Rat 1, transplanted on May 7, 2013} \\
\hline Central canal at T1-T2 & $3-4 \mathrm{~mm}$ \\
\hline Central canal at T6 & $7-8 \mathrm{~mm}$ \\
\hline Central canal at C6 & $9 \mathrm{~mm}$ \\
\hline Dorsal horn at T8-T9 & $8-9 \mathrm{~mm}$ \\
\hline Dorsal horn at L1/2 & $22 \mathrm{~mm}$ \\
\hline \multicolumn{2}{|l|}{ Attached to brainstem } \\
\hline \multicolumn{2}{|c|}{ Rat 3, transplanted on May 7, 2013} \\
\hline Dorsal horn at T2-T3 & $3 \mathrm{~mm}$ \\
\hline Dorsal horn at T6-T9 & $4-9 \mathrm{~mm}$ \\
\hline \multicolumn{2}{|c|}{ Rat 7, transplanted on May 7, 2013} \\
\hline Dorsal horn at T7 & $7 \mathrm{~mm}$ \\
\hline \multicolumn{2}{|c|}{ Side of fourth ventricle } \\
\hline \multicolumn{2}{|c|}{ Rat 9, transplanted on May 9, 2013} \\
\hline Dorsal horn at T1-T2 & $3-4 \mathrm{~mm}$ \\
\hline \multicolumn{2}{|l|}{ Attached to brainstem } \\
\hline \multicolumn{2}{|c|}{ Rat 10, transplanted on May 9, 2013} \\
\hline Central canal at T1 & $3 \mathrm{~mm}$ \\
\hline Central canal at T5 & $3 \mathrm{~mm}$ \\
\hline Dorsal horn at T7 & $6 \mathrm{~mm}$ \\
\hline \multicolumn{2}{|c|}{ Rat 13, transplanted on May 9, 2013} \\
\hline Central canal at C4 & $11-12 \mathrm{~mm}$ \\
\hline Dorsal horn at T1-T2 & $4-5 \mathrm{~mm}$ \\
\hline \multicolumn{2}{|c|}{ Rat 16, transplanted on May 14, 2013} \\
\hline Dorsal horn at T7-T9 & $4-6 \mathrm{~mm}$ \\
\hline \multicolumn{2}{|c|}{ Rat 24, transplanted on May 14, 2013} \\
\hline Central canal at C8 & $4-5 \mathrm{~mm}$ \\
\hline Dorsal horn T6-T10 & $9-14 \mathrm{~mm}$ \\
\hline \multicolumn{2}{|c|}{ Rat 25, transplanted on May 16, 2013} \\
\hline Dorsal horn at $\mathrm{T} 4$ and $\mathrm{T} 7$ & $3-6 \mathrm{~mm}$ \\
\hline Dorsal horn at T12 & $15-16 \mathrm{~mm}$ \\
\hline \multicolumn{2}{|l|}{ Fourth ventricle } \\
\hline \multicolumn{2}{|c|}{ Rat 28, transplanted on May 16, 2013} \\
\hline Central canal at C6-C8 & $5-9 \mathrm{~mm}$ \\
\hline Floor of fourth ventricle & \\
\hline
\end{tabular}

Shown are the animal number, date of transplant, location of ectopic cell masses in different rats, and the distance of the ectopic masses from the main body of the graft.

Table 2. Summary of the distribution of ectopic colonies

\begin{tabular}{lc}
\hline Location & Proportion of cases \\
\hline Central canal & 5 of $20,25 \%$ \\
Attached to surface of spinal cord & 9 of $20,45 \%$ \\
Fourth ventricle & 3 of $20,15 \%$ \\
Side of the brainstem & 2 of $20,10 \%$ \\
Total with colonies & 10 of $20,50 \%$ \\
\hline
\end{tabular}

Shown are the different locations of ectopic colonies and the proportion of cases with colonies in the indicated locations.

In addition to the graft at the injury site, we discovered masses of GFP-positive cells in locations distant from the main body of the graft. We term these ectopic colonies. Table 1 indicates the location of colonies in different rats, and Table 2 indicates the proportion of cases with colonies in the different locations.

Figure 1 illustrates ectopic colonies in one rat (rat 28) in the central canal $\sim 4-7 \mathrm{~mm}$ rostral to the main graft in a horizontal section through the block containing the lesion site and main body of the graft. The central canal was distended around the ectopic cell masses. Stalks composed of transplant-derived tissue (GFP-positive) extended between the masses. Overall, ectopic colonies were present in the central canal in horizontal sections of the lesion block in three other rats (rats 1, 3, and 10). In rat 1 , colonies were present both rostral and caudal to the injury, in rats 3 and 10 , colonies were caudal to the injury, and in rat 28, the colony was rostral to the injury.
We also discovered ectopic colonies in the central canal in cross-sections taken at cervical levels in four rats (rats 1, 13, 24, and 28). Figure $1 B$ illustrates a colony at the cervical level from the rat shown in Figure 1, $A$ (rat \#28), and $C$ illustrates an ectopic colony in the part of the central canal that extends into the caudal brainstem. The section shown in Figure $1 C$ was one of the most caudal sections taken as we sectioned the block with the brain to search for other colonies (see below). The section is partial, so to provide tissue context, Figure $1 D$ illustrates a low-power image of a section from the same region in a different rat. From this, it is evident that the section with the colony is actually in the caudal brainstem ventral to the area postrema.

We also discovered ectopic colonies attached to the surface of the spinal cord in nine rats (Table 1 ). Figure $1, F$ and $G$, illustrates a colony attached to the ventrolateral part of the spinal cord adjacent to the lateral column several millimeters caudal to the main graft in rat 25. GFP-labeled axons extended from the ectopic masses into the spinal cord parenchyma (Fig. $1 G$; more on this below). Figure $1 H$ illustrates colonies at the dorsal root entry zone at T12 on both sides in rat 28. This is from cross-sections taken caudal to the block containing the lesion.

\section{Ectopic colonies in the brain}

Next, we examined coronal sections taken at $100 \mu \mathrm{m}$ intervals throughout the brain from approximately the level of the spinomedullary junction to the frontal pole of the cortex (brains were dissected without preserving olfactory bulbs). Ectopic colonies were found in several cases (Table 1). Figure 2 illustrates the largest of the colonies in the fourth ventricle. This is the same colony shown in our initial report (Steward et al., 2014). Colonies in the fourth ventricle are particularly noteworthy because they are in a confined space in which expansion could compress surrounding structures. Axons extend from this colony into critical nuclei in the dorsal tegmentum (see below). Reconstructions of this colony revealed that it had a diameter of $\sim 500 \mu \mathrm{m}$ at its widest point and could be seen in 33 sections taken at $20 \mu \mathrm{m}$ intervals, indicating that it extended for $\sim 660 \mu \mathrm{m}$ rostrocaudally (Fig. $2 A-F$ ). Based on stereological assessment, the total volume of the colony was calculated to be $3.05 \times 10^{7} \mu \mathrm{m}^{3}$. Another colony was found in this rat on the dorsolateral side of the brainstem in a nearby section (data not shown).

Ectopic colonies were seen in the fourth ventricle in 3 of 20 rats. Figure $2 H$ illustrates a colony from a different rat, which was not tightly attached in some sections and floated free during handling of the sections. This is important to keep in mind because histological preparation involving floating sections may lead to loss of colonies from sections. Indeed, we examined the buffer in which sections from this rat were stored and found sections through this colony that had separated from the brainstem section.

In addition to the large colonies in the fourth ventricle, smaller colonies were seen in several rats attached to the lateral surface of the brainstem. Figure $1 E$ illustrates one of these in the same section shown in Figure 1C. Although we scanned sections at $100 \mu \mathrm{m}$ intervals throughout the brain, no colonies were detected rostral to the midbrain in either the ventricle or on the surface of the brain.

As noted in Materials and Methods, cell isolations and transplants were done on different days (Table 2), which constitute independent experiments. Ectopic cell colonies were seen in rats that were injected on all four of the separate days. Also, we used two different transplant methods. In Method 1, the dura mater was opened, scar tissue was removed from the injury site, and 

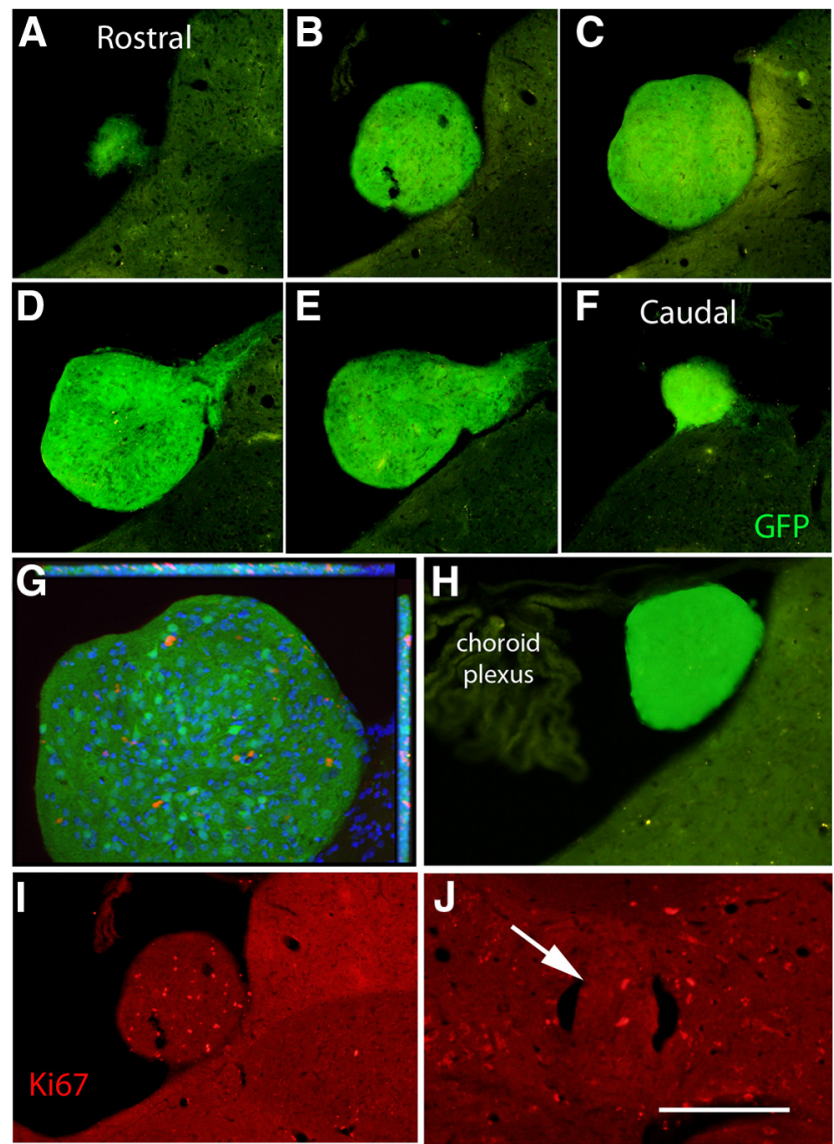

Figure 2. Reconstruction of the ectopic colony in the fourth ventricle and assessment of proliferation within colonies. $\boldsymbol{A}-\boldsymbol{F}$ illustrate spaced sections through the ectopic mass in rat 28. $\mathbf{G}$, ApoTome image of the ectopic colony in $\mathbf{C}$. Red fluorescence indicates Ki-67-positive cells, blue indicates Hoechst-stained nuclei, and green is native GFP fluorescence. $\boldsymbol{H}$, Example of an ectopic colony in the fourth ventricle from a different rat (rat 25). This is native GFP fluorescence in a section floating in buffer without immunostaining. $I$, Ectopic colony in the fourth ventricle immunostained for Ki-67. This is the same section illustrated in $\boldsymbol{B}$. Ectopic colony in the central canal immunostained for Ki-67. Scale bar: $\boldsymbol{A}-\boldsymbol{I}, 250 \mu \mathrm{m} ; \boldsymbol{J}, 125 \mu \mathrm{m}$.

cells were injected into the open injury cavity. In Method 2, multiple small holes were made in the dura mater, and injections were made through these holes. Ectopic cell colonies were seen in rats transplanted with both methods. Finally, ectopic colonies were seen in rats that were transplanted at different times after cell isolation ranging from $1.7 \mathrm{~h}$ (the shortest delay time for any transplant) to $6.8 \mathrm{~h}$. These three facts indicate that the ectopic colonies are not a rare or unusual event in this paradigm.

\section{Outgrowth of axons from ectopic colonies}

GFP-labeled axons extended from ectopic colonies in all locations. Halos of GFP-positive axons extended from the ectopic colonies in the central canal (Fig. $1 A-C$ ) and from the ectopic colonies on the surface of the spinal cord (Fig. 1G). As documented in our initial report (Steward et al., 2014), axons also extended from the ectopic colony in the fourth ventricle into the adjacent brainstem in the region dorsal to the nucleus of the solitary tract. These axons had varicosities suggestive of en passant synapses.

\section{Cell types in the colonies}

To determine the cellular composition of the ectopic colonies, sections containing colonies were immunostained with cell type- specific markers. First, we immunostained for nestin, which is a marker for neural precursors. Figure $3 A$ illustrates a colony in the central canal of the cervical spinal cord, which was immunostained for nestin and GFP and stained with Hoechst. Figure $3 B$ is an ApoTome image showing only the red channel (nestin) and blue channel (Hoechst). Nestin is strongly expressed throughout the colony.

Next, we immunostained colonies for markers of differentiated neurons, astrocytes, and oligodendrocytes. Figure $3 C$ illustrates a different section through the same colony shown in Figure 3, $A$ and $B$, immunostained for NeuN. Small- to mediumsized NeuN-positive neurons were densely packed in the colony. Immunostaining of sections with the colony shown in Figure $1 \mathrm{~A}$ for GFAP revealed GFAP-positive cells with a morphology similar to the astrocytes in the nearby spinal cord (Fig. $3 H$ ). Figure 3, $D$ and $E$, illustrate a colony in the central canal imaged for native GFP fluorescence and immunostained for APC/CC1 (a marker for mature oligodendrocyes). A few APC/CC1-positive cells are present in the colony. Figure $3, F$ and $G$, illustrate a section with a colony in the central canal imaged for native GFP fluorescence and immunostained for IBA1 to reveal microglia. IBA1-positive cells in the colony have a morphology that is very similar to IBA1-positive microglia in the parenchyma of the host spinal cord (image not shown).

Figure $3, I$ and $J$, illustrate a colony attached to the surface of the spinal cord immunostained for GFP and SMI-312 antibody (NF protein) and Hoechst. Figure $3 I$ is an ApoTome image with all three channels to document GFP fluorescence, and Figure $3 \mathrm{~J}$ is the same image showing only the red channel (SMI-312) and blue channel (Hoechst). NF-positive neurites (presumed axons) were densely packed throughout the colony. It is noteworthy that the level of NF immunofluorescence was considerably higher than in the nearby white matter of the host spinal cord. This may be because myelination of host axons impeded immunostaining.

The colony in the fourth ventricle also contained a mixture of neurons, astrocytes, and oligodendrocytes. Figure $3 \mathrm{~K}$ illustrates the colony in the fourth ventricle imaged for GFP fluorescence (green), stained for Hoechst to reveal nuclei, and immunostained for Ki-67 (pink; more on this below). Figure $3 L$ illustrates a different section through the same colony immunostained for NeuN. As in the colonies in the central canal of the spinal cord, small- to medium-sized NeuN-positive neurons were densely packed in the central region of the colony. Higher-magnification views (Fig. 3M) reveal multiple tapering processes extending from the NeuN-positive cell bodies; these have the form of dendrites. Putative dendrites were not as evident in the NeuNstained colonies in the central canal (Fig. 3C).

One noteworthy feature revealed by ApoTome images of the colonies in the central canal was what appeared to be breakdown of the ependymal layer and infiltration of cells from the colonies into the host spinal cord. Figure 4 illustrates an ApoTome image of GFP (same colony shown in Fig. $3 A, B$ ), and Figure $4 B$ illustrates Hoechst-stained nuclei. The continuous layer of nuclei marking the ependyma is interrupted dorsally and especially ventrally (Fig. 3B, arrows), and GFP-positive cells and nuclei are dispersed across the break. Evidence of a similar phenomenon can be seen in Figure 3F. Although a static image cannot confirm a process, the image suggests that the colony expanded to the point that it broke through the ependymal layer of the central canal, followed by dispersal of colony-derived cells into the nearby host spinal cord.

One question is whether different cell types present in the colonies were graft derived. This question is especially relevant 
for the cell types present in low abundance (APC/CC1). To assess this, colonies stained for different markers were assessed by ApoTome microscopy. Figure 5 illustrates ApoTome images of colonies immunostained for NeuN, GFAP, and $\mathrm{APC} / \mathrm{CC} 1$ (red fluorescence) and costained for GFP (green fluorescence). Each row of Figure 5 illustrates colonies immunostained for GFP $(A, D, G)$, the respective cell type-specific marker $(B, E, H)$, and the merged image with Hoechst staining for nuclei $(C, F, I)$. As expected, NeuNpositive cells also expressed GFP, confirming their origin from the NSC transplants (Fig. $5 A-C$ ). This is a colony in the central canal of the spinal cord, and the same was true of the colony in the fourth ventricle. The few APC/CC1positive cells that were present in the colonies were also GFP positive (Fig. 5D-F).

Surprisingly, GFAP-positive astrocytes in colonies were not double labeled for GFP (Fig. 5G-I), suggesting that they were of host origin. Nevertheless, GFPpositive/GFAP-positive astrocytes with a morphology resembling mature astrocytes were found in the host spinal cord near the transplant (data not shown). It may be that NSCs that travel to distant sites differentiate primarily into neurons and host astrocytes migrate into the colonies.

Immunostaining of the large ectopic colony in the fourth ventricle with synaptophysin revealed densely packed synaptophysin-positive puncta. Figure $6 A$ illustrates an ApoTome image of a colony immunostained for synaptophysin and GFP and stained with Hoechst, and Figure $6 B$ illustrates the same image showing only the red channel. The density of puncta in the colony was similar to that of the adjacent dorsal tegmentum of the host. As a negative control, white matter tracts in the same section, such as the medullary pyramid, contained few synaptophysin-positive puncta (data not shown). Higher-magnification ApoTome images of the same colony revealed synaptophysin-positive puncta of the expected size of presynaptic terminals (Fig. 6C). Interestingly immunostaining of a different section through the ectopic colony in the fourth ventricle for VGLUT1 and GFP (Fig. 6D) revealed only a few positive puncta in small clusters, in contrast to the nearby host neuropil (Fig. 6D,F). This suggests that synaptophysin-positive puncta are either not glutamatergic or have not matured to the point that they express the glutamatergic marker.

\section{Cell proliferation in the ectopic colonies}

In our initial report of ectopic colonies (Steward et al., 2014), we documented Ki-67-positive cells in the ectopic colony in the fourth ventricle, indicating ongoing proliferation. Because ongoing proliferation could increase the size of the ectopic mass, we
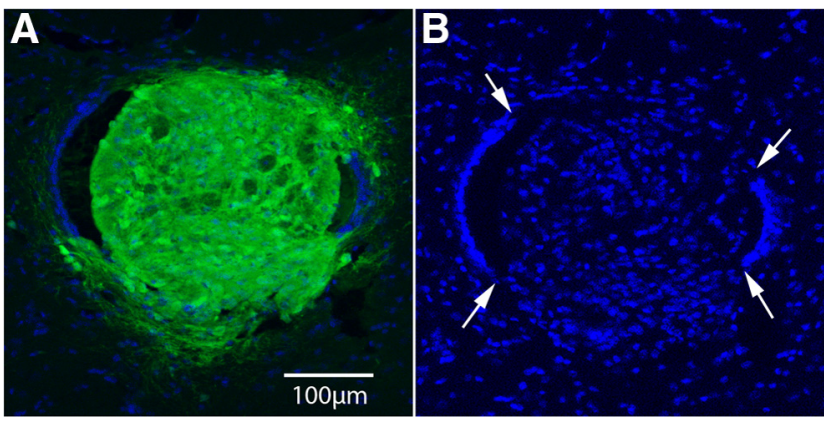

Figure 4. Disruption of the ependymal layer of the central canal and infiltration of cells from the colonies into the host spinal cord. A, ApoTome image of the colony shown in Figure $3, A$ and $B$, showing the green channel (GFP) and blue channel (Hoechst). $\boldsymbol{B}$ is same image showing only the blue channel. Arrows indicate breaks in the continuous ring of nuclei that normally define the ependymal layer of the central canal. 


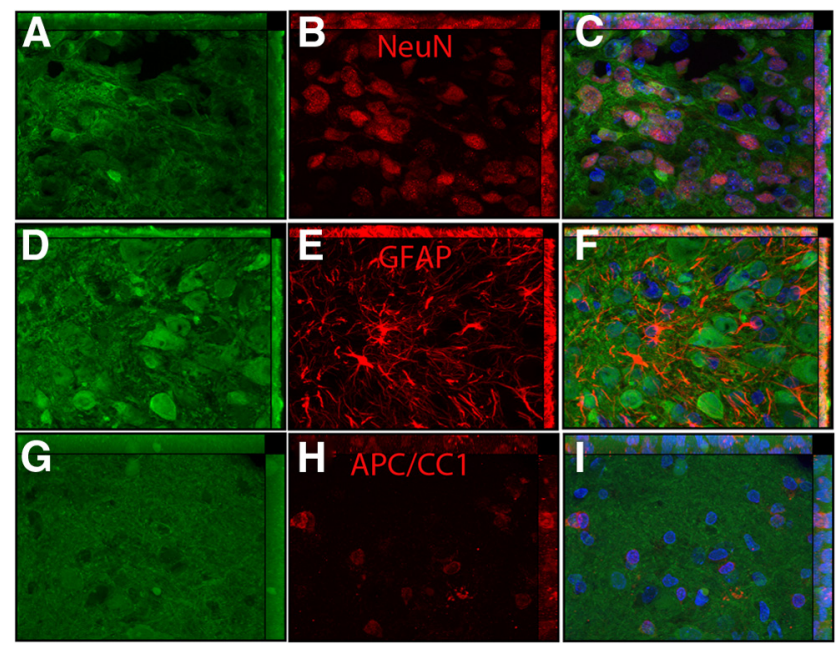

Figure 5. Assessing costaining for GFP and cell type markers with confocal microscopy. $\boldsymbol{A}$, Colony in the central canal imaged for GFP. $\boldsymbol{B}$, Same section imaged for NeuN. $\boldsymbol{C}$, Merged image of $\boldsymbol{A}$ and $\boldsymbol{B}$ and Hoechst (blue) to reveal nuclei. Arrows indicate NeuN-positive cells that also express GFP. D, Colony in the fourth ventricle imaged for GFP. $\boldsymbol{E}$, Same section imaged for GFAP. $\boldsymbol{F}$, Merged image of $\boldsymbol{D}$ and $\boldsymbol{E}$ and Hoechst (blue) to reveal nuclei. $\boldsymbol{G}$, Colony in the central canal imaged for GFP. $\boldsymbol{H}$, Same section imaged for APC/CC1. $\boldsymbol{I}$, Merged image of $\boldsymbol{G}$ and $\boldsymbol{H}$ and Hoechst (blue) to reveal nuclei.

assessed how many Ki-67-positive cells were present and the proportion of the total number of cells in the colony that were Ki-67 positive. For this, sections at spaced intervals through the ectopic colony in the fourth ventricle (Fig. $2 A-F$ ) were immunostained for Ki-67 and Hoechst. Figure $2 G$ illustrates an ApoTome image of a section to show the distribution of GFP-positive cells, Hoechst-positive nuclei, and Ki-67-positive cells throughout the depth of one section, and Figure $3 I$ illustrates another section through the same colony (the same section shown in Fig. 2B) imaged for Ki-67 only. Stereological analyses (see Materials and Methods) yielded an estimated total of 21,818 nuclei in the ectopic mass, of which 1005 ( 5\%) were Ki-67 positive. Given that the total volume of the colony is $3.05 \times 10^{7} \mu \mathrm{m}^{3}$, there would be one nucleus per $\sim 1400 \mu \mathrm{m}^{3}$ that would be a sphere with an average diameter of $\sim 14 \mu \mathrm{m}$. This has good face validity with the images.

Ki-67-positive cells were also present in colonies in other locations; Figure 2J illustrates Ki-67-positive cells in the colony in the central canal at the cervical level. Ki-67-positive cells were also seen at approximately similar density in the colonies attached to the surface of the spinal cord (data not shown).

There were not enough sections through other colonies to perform systematic stereological analyses because sections through other colonies were used for other stains. Nevertheless, volumes can be estimated based on reasonable assumptions. For example, assuming that the mass in the central canal shown in Figure $2 A-E$ is spherical, the volume would be $1.101 \times 10^{7} \mu \mathrm{m}^{3}$. This may be an underestimate if the colony actually is elongated along the central canal like the one in Figure $2 H$. Assuming that the colony in Figure $2 \mathrm{H}$ is football shaped, it can be modeled by two cones with apposed bases, yielding an approximate volume of $1.201 \times 10^{7} \mu \mathrm{m}^{3}$. Assuming that the colony on the surface of the spinal cord shown in Figure $2 I$ is the shape of a rectangular cuboid with similar length and width, its volume would be $1.772 \times 10^{7} \mu \mathrm{m}^{3}$.

\section{Discussion}

This study extends the findings of our brief report (Steward et al., 2014) of ectopic colonies when growth factor-treated NSCs are transplanted into a spinal cord transection site. Ectopic colonies contain up to tens of thousands of cells, including differentiated neurons, astrocytes, and a few oligodendrocytes, and the neurons extend axons into the parenchyma of the host. Synaptophysinpositive puncta in the colonies suggest the presence of large numbers of presynaptic terminals. Colonies are strongly positive for nestin, a marker of neural precursors, and contain Ki-67-positive cells, suggesting continuing expansion at 2 months after transplantation.

\section{Do NSCs have a previously unrecognized capacity to migrate} and form ectopic cell masses or is colony formation attributable to unique conditions of the experiment?

Previous studies involving transplants of dissociated cells or blocks of tissue from fetal rat spinal cords have not reported ectopic colonies at sites distant from the transplants. The lack of reports of ectopic colonies may mean that they did not form, that they formed but were not noticed, or that they were noticed but were not reported. In this regard, it is noteworthy that Tuszynski et al. (2014) did not notice ectopic colonies in their material but confirmed their existence after learning of our results. It is easy to miss unusual things in anatomical material unless one is specifically looking for them.

Ectopic colonies may not have been detected previously because robust genetic markers for transplanted cells have only recently become available. However, colonies were not reported in a study (Lepore and Fischer, 2005) of transplants of E14 spinal cord and E13.5 spinal cord-derived neural precursor cells (NPCs) from rats expressing human placental alkaline phosphatase. Colonies also were not reported in preclinical animal studies of human fetal cells derived from 8- to 12-week-old fetuses (Uchida et al., 2000; Yan et al., 2007; Hooshmand et al., 2009; Jin et al., 2011). However, it is not clear whether the histological analyses in these studies would have detected the kind of colonies we show here if they were present. In particular, it is not known how many previous studies even searched for ectopic masses in the brain. There would be no reason to suspect their existence until our report of their existence. The present characterization of ectopic colonies reveals what to look for in future studies.

Regarding the possibility that colony development reflects the unique conditions of the experiment, in the response to our report (Tuszynski et al., 2014), the authors speculate that pressure pulses from the Picospritzer used for transplantation could have led to broad dispersal of the cells. However, colonies were found in rats when the dura mater was opened to deliver cells (transplantation Method 1). With the dura mater open, pressure pulses would be dissipated. Regardless, it is unlikely that pressure pulses could drive cells from a thoracic lesion cavity into the fourth ventricle.

It may not be the dispersal per se that is the problem but rather the continued proliferation of cells to form large cell masses. In this regard, NSCs were treated with multiple growth factors and were grafted in a fibrin matrix, which has been used for prolonged release of growth factors (for review, see Spicer and Mikos, 2010). Tuszynski et al. (2014) report that grafts of NSCs that were not treated with growth factors survived poorly and did not expand to fill the lesion cavity. The growth factor cocktail may be required for extensive survival, expansion, and robust axon outgrowth that was so striking in the report of Tuszynski et al. (2014) but could also cause cells that have dispersed to continue proliferating in other parts of the nervous system. The question is 
whether a balance can be found that allows survival, expansion, and robust axon outgrowth in the absence of colony formation.

Previous reports have demonstrated extensive cell death after fetal transplantation into a spinal cord lesion site (Theele et al., 1996; Lepore and Fischer, 2005). The injury site is then repopulated, perhaps by neuronal and glial precursors (Lepore and Fischer, 2005), or a more primitive cell type (Cai et al., 2002). NSCs treated with growth factors may contain highly proliferative cells that respond to an initial wave of cell death with a prolonged proliferative response that continues even after cells migrate to distant sites.

The fact that colonies were located in the central canal, on the surface of the spinal cord, and attached to structures bordering the ventricles in the brain suggests that the cells traveled via the CSF. Dispersal of cells has been studied previously after intrathecal and intraventricular transplantation in rodent models of spinal cord injury and multiple sclerosis, including studies using E13.5 rat NPCs. After delivery of alkaline phosphatase-expressing NPC via lumbar puncture, cells accumulated at the injury site but were also found in other regions of the CNS localized near the ventricular system (Lepore et al., 2005). Cells were not reported in the central canal, however. After intraventricular injections of murine SVZderived stem cells in an experimental autoimmune encephalomyelitis model of multiple sclerosis, cells were found in submenengial areas of the brain and spinal cord, but none of the studies reported multicellular masses after intrathecal transplantation.

The size of the colonies makes it highly unlikely that the entire cell mass moved because the colonies are much larger than the spaces through which they would have moved (especially in the case of the central canal). This suggests that the cells attached and proliferated to expand the colony, that there were initial pioneers with other cells gathering at the site, or that the size of the mass increased as a result of differentiation. Indeed, all of these may occur. CSF functions as part of the endogenous stem cell niche, particularly in the delivery of proliferative signals (Lehtinen et al., 2011). Thus, CSF may be the vehicle for both the delivery of founding cells and factors that favor proliferation. The presence of Ki-67-positive cells in the ectopic masses and strong nestin immunoreactivity indicate ongoing cellular proliferation and the presence of young cells, suggesting that the colonies are still growing 2 months after transplantation.

It is noteworthy that common sites for colony formation were the central canal and fourth ventricle. It may be that, if cells disperse via the CSF, certain sites may favor docking or favor proliferation. It is noteworthy that stem cells exist in periventricular and peri-ependymal niches, and the prevalence of colonies in these locations may indicate that NSCs seed and proliferate in these niches.

\section{Possible physiological consequences}

Synaptic connections between graft-derived neurons and host neurons could trigger abnormal activity. Axons extended from the colony in the fourth ventricle into the area around the nucleus of the solitary tract and the area postrema, which are critical relays for autonomic reflexes and vomiting, respectively. Colonies at the dorsal root entry zone extend axons into the dorsal horn, which contains second-order relay neurons conveying pain and temperature sensation. Abnormal connections in these critical sites could create abnormal activity.

\section{Implications for ongoing translational programs involving stem cells}

Recent preclinical studies of human NSCs have shown promise for spinal cord injury (Cummings et al., 2005; Keirstead et al., 2005; Hooshmand et al., 2009; Salazar et al., 2010; van Gorp et al., 2013), and NSCs are currently being tested in clinical trials (Dunnett and Rosser, 2014). Although preclinical studies and completed phase I clinical trials (Selden et al., 2013; Feldman et al., 2014) using human NSCs have not reported the ectopic colonies shown here, human stem cells proliferate and exit the cell cycle more slowly than rodent stem cells, so colonies of human cells may develop over longer periods of time. Cycle times of mouse embryonic stem cells are $8-10$ versus $26-30 \mathrm{~h}$ for human embryonic stem cells (White and Dalton, 2005), and cycle times for human NSCs are 85-114 h (Svendsen et al., 1998; Kanemura et al., 2002). To be certain that NSCs being used in clinical trials do not have a capacity for colony formation may require longer follow-up times after transplantation.

Two case reports reveal that transplants of human fetal tissue can lead to neural cell masses and that symptoms may not appear for years. A cellular mass was found impinging on the internal capsule 2 years after transplant in an individual with Huntington's disease who received transplants of human midbrain as part of a multicenter clinical trial (Keene et al., 2009). Multifocal cell masses were found 4 years after transplantation in an individual with ataxia telangencia who received a transplant of fetal neural cells (Amariglio et al., 2009); the nature of the transplanted cells is unclear (Jandial and Snyder, 2009; Amariglio and Rechavi, 2010). 
Cell masses growing anywhere in the nervous system have the potential to cause harm, and growth of masses in the central canal and fourth ventricle could be especially problematic. We recommend a reexamination of the potential of colony formation by transplanted NSCs with the new knowledge of what to look for and vigilance for signs and symptoms that might occur if such masses developed in people receiving NSC transplants in clinical trials, especially young individuals with an expected survival of decades after transplantation.

\section{References}

Amariglio N, Rechavi G (2010) On the origin of glioneural neoplasms after neural cell transplantation. Nat Med 16:157; author reply 157-158. CrossRef Medline

Amariglio N, Hirshberg A, Scheithauer BW, Cohen Y, Loewenthal R, Trakhtenbrot L, Paz N, Koren-Michowitz M, Waldman D, Leider-Trejo L, Toren A, Constantini S, Rechavi G (2009) Donor-derived brain tumor following neural stem cell transplantation in an ataxia telangiectasia patient. PLoS Med 6:e1000029. CrossRef Medline

Cai J, Wu Y, Mirua T, Pierce JL, Lucero MT, Albertine KH, Spangrude GJ, Rao MS (2002) Properties of a fetal multipotent neural stem cell (NEP cell). Dev Biol 251:221-240. CrossRef Medline

Cummings BJ, Uchida N, Tamaki SJ, Salazar DL, Hooshmand M, Summers R, Gage FH, Anderson AJ (2005) Human neural stem cells differentiate and promote locomotor recovery in spinal cord-injured mice. Proc Natl Acad Sci U S A 102:14069-14074. CrossRef Medline

Dunnett SB, Rosser AE (2014) Challenges for taking primary and stem cells into clinical neurotransplantation trials for neurodegenerative disease. Neurobiol Dis 61:79-89. CrossRef Medline

Feldman EL, Boulis NM, Hur J, Johe K, Rutkove SB, Federici T, Polak M, Bordeau J, Sakowski SA, Glass JD (2014) Intraspinal neural stem cell transplantation in amyotrophic lateral sclerosis: phase 1 trial outcomes. Ann Neurol 75:363-373. CrossRef Medline

Hooshmand MJ, Sontag CJ, Uchida N, Tamaki S, Anderson AJ, Cummings BJ (2009) Analysis of host-mediated repair mechanisms after human CNSstem cell transplantation for spinal cord injury: correlation of engraftment with recovery. PLoS One 4:e5871. CrossRef Medline

Jandial R, Snyder EY (2009) A safer stem cell: on guard against cancer. Nat Med 15:999-1001. CrossRef Medline

Jin Y, Neuhuber B, Singh A, Bouyer J, Lepore A, Bonner J, Himes T, Campanelli JT, Fischer I (2011) Transplantation of human glial restricted progenitors and derived astrocytes into a contusion model of spinal cord injury. J Neurotrauma 28:579-594. CrossRef Medline

Kanemura Y, Mori H, Kobayashi S, Islam O, Kodama E, Yamamoto A, Nakanishi Y, Arita N, Yamasaki M, Okano H, Hara M, Miyake J (2002) Evaluation of in vitro proliferative activity of human fetal neural stem/ progenitor cells using indirect measurements of viable cells based on cellular metabolic activity. J Neurosci Res 69:869-879. CrossRef Medline

Keene CD, Chang RC, Leverenz JB, Kopyov O, Perlman S, Hevner RF, Born DE, Bird TD, Montine TJ (2009) A patient with Huntington's disease and long-surviving fetal neural transplants that developed mass lesions. Acta Neuropathol 117:329-338. CrossRef Medline

Keirstead HS, Nistor G, Bernal G, Totoiu M, Cloutier F, Sharp K, Steward O (2005) Human embryonic stem cell-derived oligodendrocyte progenitor cell transplants remyelinate and restore locomotion after spinal cord injury. J Neurosci 25:4694-4705. CrossRef Medline

Lehtinen MK, Zappaterra MW, Chen X, Yang YJ, Hill AD, Lun M, Maynard
T, Gonzalez D, Kim S, Ye P, D’Ercole AJ, Wong ET, LaMantia AS, Walsh CA (2011) The cerebrospinal fluid provides a proliferative niche for neural progenitor cells. Neuron 69:893-905. CrossRef Medline

Lepore AC, Fischer I (2005) Lineage-restricted neural precursors survive, migrate, and differentiate following transplantation into the injured adult spinal cord. Exp Neurol 194:230-242. CrossRef Medline

Lepore AC, Bakshi A, Swanger SA, Rao MS, Fischer I (2005) Neural precursor cells can be delivered into the injured cervical spinal cord by intrathecal injection at the lumbar cord. Brain Res 1045:206-216. CrossRef Medline

Lu P, Wang Y, Graham L, McHale K, Gao M, Wu D, Brock J, Blesch A, Rosenzweig ES, Havton LA, Zheng B, Conner JM, Marsala M, Tuszynski MH (2012) Long-distance growth and connectivity of neural stem cells after severe spinal cord injury. Cell 150:1264-1273. CrossRef Medline

Salazar DL, Uchida N, Hamers FP, Cummings BJ, Anderson AJ (2010) Human neural stem cells differentiate and promote locomotor recovery in an early chronic spinal cord injury NOD-scid mouse model. PLoS One 5:e12272. CrossRef Medline

Selden NR, Al-Uzri A, Huhn SL, Koch TK, Sikora DM, Nguyen-Driver MD, Guillaume DJ, Koh JL, Gultekin SH, Anderson JC, Vogel H, Sutcliffe TL, Jacobs Y, Steiner RD (2013) Central nervous system stem cell transplantation for children with neuronal ceroid lipofuscinosis. J Neurosurg Pediatr 11:643-652. CrossRef Medline

Sharp KG, Yee KM, Steward O (2014) A re-assessment of long distance growth and connectivity of neural stem cells after severe spinal cord injury. Exp Neurol 257:186-204. CrossRef Medline

Spicer PP, Mikos AG (2010) Fibrin glue as a drug delivery system. J Control Release 148:49-55. CrossRef Medline

Steward O, Sharp KG, Matsudaira Yee K (2014) Long-distance migration and colonization of transplanted neural stem cells. Cell 156:385-387. CrossRef Medline

Svendsen CN, ter Borg MG, Armstrong RJ, Rosser AE, Chandran S, Ostenfeld T, Caldwell MA (1998) A new method for the rapid and long term growth of human neural precursor cells. J Neurosci Methods 85:141-152. CrossRef Medline

Theele DP, Schrimsher GW, Reier PJ (1996) Comparison of the growth and fate of fetal spinal iso- and allografts in the adult rat injured spinal cord. Exp Neurol 142:128-143. CrossRef Medline

Tuszynski MH, Wang Y, Graham L, Gao M, Wu D, Brock J, Blesch A, Rosenzweig ES, Havton LA, Zheng B, Conner JM, Marsala M, Lu P (2014) Neural stem cell dissemination after grafting to CNS injury sites. Cell 156:388-389. CrossRef Medline

Uchida N, Buck DW, He D, Reitsma MJ, Masek M, Phan TV, Tsukamoto AS, Gage FH, Weissman IL (2000) Direct isolation of human central nervous system stem cells. Proc Natl Acad Sci U S A 97:14720-14725. CrossRef Medline

van Gorp S, Leerink M, Kakinohana O, Platoshyn O, Santucci C, Galik J, Joosten EA, Hruska-Plochan M, Goldberg D, Marsala S, Johe K, Ciacci JD, Marsala M (2013) Amelioration of motor/sensory dysfunction and spasticity in a rat model of acute lumbar spinal cord injury by human neural stem cell transplantation. Stem Cell Res Ther 4:57. CrossRef Medline

White J, Dalton S (2005) Cell cycle control of embryonic stem cells. Stem Cell Rev 1:131-138. CrossRef Medline

Yan J, Xu L, Welsh AM, Hatfield G, Hazel T, Johe K, Koliatsos VE (2007) Extensive neuronal differentiation of human neural stem cell grafts in adult rat spinal cord. PLoS Med 4:e39. CrossRef Medline 